\title{
Tiyatro Oyunları Yaratıcılı̆̆ı Teşvik Eder ve Yaratıcı Oyun Davranışına Gereksinim Duyar. Bu Husus Bertolt Brecht'in KÖTÜ ve ASOSYAL BAAL Örneğinde Göstẹrilmiştir ${ }^{* *}$
}

\author{
Gerd Koch* \\ Alice Salomon Fakültesi
}

\begin{abstract}
$\ddot{O}_{z e t}$
Pedagoji, eğitim bilimleri metodu ve uygulamast olarak tiyatroya, tiyatro metinlerine, tiyatro oyunlarına ve sahnelemelere dayanir. Bu, sadece okullardaki veya çalı̧̧ma topluluklartndaki edebiyat dersinde ve bir tiyatro metnini temsil edilecek şekle sokmak isteyen araşttrma projelerinde gerçekleşmez. Tiyatronun iletişimsel-yaratıcı modeli daha ziyade okul dışındaki eğitim süreçlerini ve araştırma ve inceleme projelerini yaplandırtr ve geleneksel tiyatroyu tamamlar. Pedagojinin teori ve uygulamadaki bu yaklaşımt Almancada tiyatro pedagojisi olarak adlandırtlmaktadır. Bu hususun üniversite öğrencilerinin yüksek öğreniminde yaratıct şekilde ve farklı şekillerde nasıl uygulanabileceği, Bertolt Brecht'in BAAL adli tiyatro oyunu fragmanı örneği üzerinde aşağıda gösterilecektir. Brecht'in öğretici oyun teorisi ve uygulamasindaki fikirleri ortaya konacak ve yüksek okullarda öğretim ve öğrenmeye ilişkin çalışma önerilerinde bulunulacaktır.
\end{abstract}

Anahtar sözcükler:Tiyatro oyunlarl, Bertolt Brecht, ögretici oyun

\section{Tiyatro Pedagojisi}

Reiner Steinweg'in başlattığı Brecht öğretici oyun (Lehrstiuck) tartışması ve barış araştırması ve eğitimi bağlamında eğitim bilimcisi ve eski yüksek öğretim kurulu üyesi Horst Rumpf tarafından önerilen sahne yaklaşımı eğitimde, öğrenmede ve tecrübe edinmede yeni bir boyut ortaya çıkarmıştır. "Süjelerin tecrübe edildikleri dünyada oluşumlan üzerine yapılan çalı̧smada ortaya konan bu sahne yaklaşımı safi içeriğiyle sınırlandınılmasından daha fazla zamana mal olur. Öğrenme süreçlerindeki hassas noktaların ve aşamaların araştırılmasında denemeler yapmak, farklı yollardan gitmek ve yanlış yollara sapmak zaman kaybı olarak nitelendirilemez...(Rumpf, S. 165). Araşturma, eğitim, öğretim ve öğrenme tiyatronun oluşturduğu eğitim olayında bir bütünlük oluşturur. Almancadaki klasik eğitim (Bildung) kavramı anlamının bir kısmım bunun içinde barındırır: Bir şeyle yapılır, oluşturulur, tesis edilir; Bir şeyin estetik, imgesel ve idealistlik niteliği vardır; Bir resim sanat eseri olarak çok anlamlı bir oluşumdur; eğitim prizma şeklinde bir oluşumdur ve yorumlara olanak sağlar. Tiyatro üzerine kurulu olan eğitim süreçleri, İtalyancada isimlendirildiği gibi "biçimlendirme" (formazione), "kültür" (cultura), "eğitim" (educazione) ve oluşturma (istruzione) gibi farklı unsurlan birleştirir.

\footnotetext{
"* Bu makalenin Almanca'dan Türkçe'ye çevirisi Erdem Karabulut tarafından yapılımıştır.

* Prof. Dr.Alice Salomon Fakuiltesi, E-posta: Koch@asfh-berlin.de
} 
"Tiyatro pedagojisi, tiyatroya ilişkin olan hususların ve tiyatroculuğun öğretim ve öğrenme süreçlerinde kullanılması anlamına gelir. Burada öğretim ve öğrenim süreçleri ... bireydeki ve bireyler arasındaki bilgi ve davranışın toplumsal ve /veya sosyal değişim süreçleridir. Tiyatroya ilişkin olmayı, tiyatroculuğu veya tiyatro ilkesini günlük hayatta karşılaşılan ve sanatsal nitelik taşıyan hususların gösteri, davranış, temaşa ve temsil şekli olarak anlamak istiyorum: Sokakta yaşanılan sahneler ile tiyatro sahneleri tupkı bir ayinin veya sürecin kutlanması ya da meclis yemeğinde siyasilerin gösterdikleri mimikler gibi haturda tutulmalıdır..." (Koch 1995, s. 11)

Gera tiyatro okulundan Mario Portmann şöyle der: “ Tiyatro pedagojisi tiyatro aracılığıyla eğitmez, bilakis içimize, buluşlarımıza ve yaratıcılığımıza giren engelleri ve zorlamaları ortadan kaldırmak ister".

Tiyatro pedagogu olarak Bertolt Brecht'in Kötü ve Asosyal Baal oyununun taslakları, sahneleri ve fragmanlan ile deneyler yaptım. Bunu yaparken öğretici oyun kurallarına (Bakınız. Steinweg 1995, 2004) sıkı sıkıya bağlı kalmadım, bunun yerine Brecht'in her zaman mevcut olan metin taslağını tiyatro-oyun yaklaşımı olarak ele aldım, yani metni oyunun bir parçası olarak uyguladım. Bu yaklaşımın ele alınması gerekir, ancak bu yaklaşıma mutlaka uyulacak diye bir zorunluluk yoktur: Bir yaklaşımı ele almak ona biat etme ve bağlı olmak anlamına gelmez. Brecht'in tiyatro metinlerini tiyatroda kullanılacak taslaklar olarak alıyorum.

Brecht 1938 yulında şöyle yazmışt:: "Öğrenme kabul etme işlemi olduğu kadar bir uzaklaştırma işlemidir. Bir eleştiri işlemidir. Yani ben de aymsım yaparım ve daha iyisini yaparım düşüncesini oluşturmaktur. Öğrenme, beni değiştirdiği halde ben olarak kalmamı sağlamaktur."

\section{Brecht'in Öğretici Oyun Teorisi ve Uygulamasına Îliş̧kin Görüşleri ( Öğrenme oyunları (learning plays) kavram da Brecht tarafindan ifade edilmiştir.)}

"Öğretici oyun, oyun yoluyla öğretir, ancak seyredilmesi yoluyla öğretmez. Bir öğretici oyun için ilke olarak seyirciye ihtiyaç duyulmamakla beraber seyirci de doğal olarak değerlendirilebilir. Öğretici oyunun temelinde oyun oynayan kişinin belirli davranış biçimlerini sergilemesi, belirli tutumlan takınması ve belirli konuşmaları yapması sonucunda toplumsal olarak etkilenebileceği beklentisi yatar. Burada yüksek nitelikteki ömeklerin taklit edilmesi ile farklı bir oyunla bu tür örneklerin daha iyi sergilenebileceği yönündeki bir eleştiri büyük bir rol oynamaz. Toplumsal olarak olumlu değerlendirilebilecek davranıs ve tutumların temsil edilmesine kesinlikle gerek yoktur. Asosyal davranış ve tutumların da (mümkün olduğunca harika bir şekilde) temsil edilmesinin eğitici bir etki doğurabileceği göz önünde tutulmalıdır. 
BU HUSUS BERTOLT BRECHT' in KÖTÜ ve ASOSYAL BAAL ÖRNEĞINNDE GÖSTERILMIȘTIR

Öğretici oyunların sabit bir formatı vardır, ancak özgün ve güncel unsurlar içerisine dâhil edilebilir. " (Brecht, Teoriye ilişkin, s. 1024, Orijinal Olmayan İbareler). Öğrenme öğretimin içinde bulunmalıdır. Öğretici oyunlar sadece vecizeli bir ahlakı resimlerle donatan temsiller değildir. Öğretici oyunlar araştırma da yapar, bu nedenle çözümlerin çok yoğun ve çok sade şekillere sokulması gerekli değildir. "(Brecht nach Krabiel, S. 298). Özellikle metin türlerinin tam olmaması, parçalı olması ve harekete geçirici karakteri öğretici oyunları tiyatro pedagojisi çalışması için değerli hale getirir.

Brecht 1943 yılının başlarında Amerika'da sürgünde yaşadığı suralarda şunları yazmıstı: Yeni bir arkadaşlık. Lowa'da işçilere ve izcilere (Scouts) verdiği lider davranışı eğitimine beni davet eden Kurt Lewin Kötü ve Asosyal Baal oyunuma ilgi duyuyordu (Brecht Journale II, S. 150). Brecht gibi sürgünde yaşayan ve deneysel sosyal psikolojinin kurucularindan olan Kurt Lewin 1939 yılında "Sosyal alanla ilgili deneyler" başlıklı bir yazısında sosyal çatışmalann çözümüne ilişkin olarak şunları yazmıștı: "Fizik ve kimya alanlarında yapılan bilimsel deneyler gibi sosyoloji ve sosyal psikoloji alanlannda da bilimsel deneyler yapmanın mümkün olacağı kanaatindeyim. Gerçek ampirik bir alanın tüm esaslı unsurlanna sahip olan ve fiziksel türde olmamasına karşın fizik alanında olduğu gibi geometri ve matematik alanlanında faaliyet gösteren araştırmacıların dikkatini çekmesi gereken bir sosyal alanı bulunduğu görüşündeyim. Sosyal alanin algilanması ve sosyal alandaki olaylann yasalarmın ve dinamiklerinin deneysel ve kavramsal olarak araşturılması teori ve uygulama açısından büyük bir önem arz eder. “ (Lewin, s.41). "Bilimsel sosyolojinin ve sosyal psikolojinin deneylerin ampirizm teorisiyle yakun bağlantısı temelinde insan hayatının iyileştirilmesinde doğa bilimlerinin yaptığı kadar veya daha fazla katku sağlayabileceği kanaatindeyim. Ancak gerçekçi ve mistik olmayan bu tür bir sosyal bilimin gelişmesi ve verimli bir şekilde uygulanma olanağı bulunması akla inanan bir toplumun var olmasın gerektirir. “ (Lewin, s.52). Dünya Lewin için Brecht' in ifadesiyle emin ve dostane bir kalış yeri olmalıdır. "Akla inanma demokrasiye inanma anlamına gelir, çünkü demokrasi aklıyla düşünen kişilere eşitlik sağlar. Bu nedenle "aklın" ilk olarak Amerikan ve Fransız devrimleri sırasında demokrasinin oluşmasıyla modern toplum içerisinde taht kurmaya (yer etmeye) başlaması tesadüf değildir. Aym şekilde faşizmin her devlette ilk olarak ortaya koyduğu eylemi ile "aklın" oturduğu bu tahttan resmi olarak ve açıkça indirilmesi ve eğitim alanında ve yaşamın anaokulundan (Kindergarten) ölüme kadar olan bölümünde aklın yerine duyguların ve itaatin her şeyi belirleyen ilkeler haline getirilmesi de tesadüf değildir. " (Lewin, s.52)

7.3.1941 tarihinde Brecht tiyatro pedagojisi ile ilgili olarak şunlan yazmıştır: “ Kötü ve Asosyal Baal öğretici oyunlanm yazmamı engelleyen büyük yanılgının temelinde sosyalizmi 
büyük düzen olarak tanumlamam yatuyordu. Hâlbuki sosyalizmin büyük üretim olarak tanımlanması daha pratik bir anlam ifade eder. Üretim burada tabî ki en geniş anlamıla alınmalıdır ve tüm insanlanın üretkenliğinin tüm bağlanndan kurtarılması için mücadele edilmelidir. Ürünler insanın ekmeği, lambaları, kulübesi, müzik parçaları, satranç hamleleri, teni, karakteri, oyunları vs. vs.." (Brecht Joumale I, s.468, Orijinal İbareler).

Dieter Schmidt'in Bertolt Brecht'in Kötü ve Asosyal Baal adlı eserinin fragmanlann 1969 yılında yayınlaması tiyatro pedagojisi çalışması açısından bir şanstı: Bu metinler Brecht'in dâhiyane ön eseri Baal ile kanş̧ırılmamalıdır. Gerçi Kötü ve Asosyal Baal fragmanlanında bu esere ilişkin işaretler vardur ve Brecht tüm hayatı boyunca Baal konusuyla uğtaşmıştır. Bu metinler eser baskısında bulunmaz, 1997 yılından beri Berlin ve Frankfurt büyük yorumları baskısınin onuncu cildinde yer alur.

Schmidt'in sunduğu Kötü Baal fragmanlan koleksiyonu rol oyunlarını teşviki ile başlar: Baal konuk/fahişe/tüccar(boğa)/mühendis(sadece deney yapmak isteyen)/yardıma muhtaç-yalvaran bir kişi(sömürülmek isteyen)/doğa sever/demagog/işçi(grev kuncı)/anne/tarihçi/asker/aşık rahip/aşık memur/ iki palto olarak görünür. " (Brecht Baal, s.78)

$\mathrm{Bu}$ oyun talimatı bilinçli ya da tesadüfî olarak başlangıçta bulunur. Tiyatro pedagojisi açısından doğru vurgu yapılır. Oyuncular kendilerini eş zamanlı olmadan rolleri değiştirerek oynayacaklan oyunlara daha başlangıçta ayarlamak zorundadır. Böylece metodolojik bir unsur katılmıştır ve bu unsurun tiyatro ve/veya oyun pedagojisindeki diğer fikirlerle genişletilmesi ve somutlaşturılması gerekmektedir. Yani oyuncu yeteneği öğretici oyun pedagojisinde de uygulanmalıdır. Bu durum özellikle fragman şeklindeki ve soyut kalan sahnelerin oyun fikri olarak alınması halinde önemlidir.

\section{KÖTÜ BAAL}

Pasaport memuru olarak. Bir kadın erkek kardeşinin hayatı için mücadele eder. Memur tüm formlan doldurur. Çok acele edilmesi gerekir (Top patlaması sesi, saat sesi) (Brecht Baal, s.81).

Brecht'in öğretici oyun teorisine göre bu tür sahneler üstün nitelikte farklı bir oyun tarzının sergilenmesini, araştırma yapılmasını ve özgünlüğün oyun içine sokulmasını gerektirir. Daha güçlü hazurlanan sahneler farklı bir şeyi, yani kendi öykülerinin ve yaşam sahnelerinin yaratılmasını teşvik eder. (hatırlama çalışması ile aynı), Örneğin Brecht'in 1954 yılının yaz mevsiminde yazdığı Kötü Baal oyununun son sahnesinde olduğu gibi:

"Bir adam içeri girer.

ADAM: Bay Inzipient. Bugün büroya gelmenize gerek yok. 
Ona mavi bir mektup uzatır. 20 Fenik alayım. Ona mektubu verir.

BAAL yatağa uzantr: İçinde ne var, Baumann?

ODACI okur: Bay Baal! Sizin sınıfınızdaki dahiler için işini yapmaktan günlerce imtina eden bir yazıcının işi kadar yorucu olan bir iş görev sorumluk duygusu ile bağdaştırılamayacağı için, 1 Hazirandan itibaren belediyedeki görevinizden alındınız. İmza: Başkanın kendisi. Bay Inzipient üzgünüm.

BAAL Baumann, rüyalanmda bazen derin ve karanlık bir göl görüyorum.

ODACI: Yaşamak zorunda olmama rağmen bu şartlar altunda 20 fenikten vazgeçiyorum. Şerefli ol! Dişar f̧ıar.

BAAL güler. "(Brecht Baal, s.90 f.)

$\mathrm{Bu}$ tür metinler kolektif deneysel oyun sürecindeki yönlendirici unsurlardır. $\mathrm{Bu}$ unsurlar yetenekler için de uygulanabilir (Brecht'in Fatzer adlı oyununda olduğu gibi farklı oynama ile aynıdır. Baal konusu başka bir oyun kuralını ortaya çıkarır: mutabık olmak mutabık olmamak anlamina da gelir).

Baal fragmanlarında özellikle şu kavram veya konular içerik ve/veya metodolojik olarak bulunur: Efendi ve hizmetçi, birey ve grup, bağımlılıklar, zenginlik ve yoksulluk, anlamlılık ve maddi ilgi duymaya karşı icra edilen sanat, olumlu model ve arzulanan asosyallik, oluşturma/bozma, sökme/takma, toplumsal korku merkezlerinde çalışma vs.

Diğer perspektifler, Brecht'in fragmanlarının Germanistik ve tiyatro biliminde ele alınmasında davranışa yönelik tiyatro pedagojisi perspektiflerinden daha önemlidir. Öğretici oyunlan kendi kendine öğrenen gruplara dağıttığım oyun talimatlanndan bazılarım aşağıda ifade edeceğim:

\section{Fragman Halindeki Oyunlarda Kullanulacak Talimatlar}

* Öğretici oyunun bölümleri işlense veya farklı tiyatro oyun gruplannda iş bölümlü olarak oynansa dahi, ögretici oyun bir bütün olarak bilinmelidir.

* Çok sayıda provanın ve mimik denemelerinin yapılması önemlidir. Oyunla ilgili bir fikre çok hızlı bir şekilde kapılmamak gereklidir. Öğretici oyun oynayarak öğretir.

* Dinlenme araları iyi belirlenmeli ve gerçektenden de dinlenmek için, oyun oynayan kişiyi oturtmak için kullanılmalıdır. Yani oyuncu nefes nefese kalmadan önce ara verilmelidir.

* Konuşma devreleri oyun devlerinden ayrılmalıdır. Oyunculann gerçekliği oyun dokusu içine katulmalıdır. Farklı uygulamalara olanak sağlayan ve herkese açık olan öğrenme süreçleri 
düzenlenmelidir. "Çelişkiler umutlanmızdır." (Brecht Üç kuruşluk Dava, s. 448). Sorular cevaplardan daha önemlidir. Oyun sergilemek sadece dinlemek ve izlemekten daha iyidir.

* Öğretici oyunların davranış denemeleri ve kendiliğinden anlaşlan teklifler olduğu yeterince vurgulanamaz. Bunlarla çalışmalarda üretici ve tüketiciler arasındaki ayrımlar ortadan kaldınlmalıdur. Tartışmalı bir üretim olayı gerçekleşmemelidir. Oyunculanın sosyal ve estetik durumlan eleştirilebileceği gibi oyuncuların form durumu da dikkate alınabilir.

* Oyunlar, tiyatro ortamında gerçekleşmesine karşın oyuncular için düşünülmemiştir.

* (Her ne kadar böyle bir korku olsa da) Oyun oynamaktan korkulmamalıdır. Oyunu yöneten kişi olarak bir tiyatro oyununu kendisi ilk defa oynadığı sırada yaşadığı ilk güvensizlik duygusunu ve "eşik korkulanın" hatırda tutmalıdır. Tiyatro oynama zor yapılabilen basit bir şeydir.

* Öğretici oyunlar, yeni bir iletişim için doğrudan uygulama sahasıdır. Öğretici oyunlar kişileri, metinleri, şekilleri, içerikleri, niyetleri, ruhsal durumlan diyalektik olarak, eş zamanlı olmadan ve çelişkili olarak ele almak anlamma gelir. Ve öğretici oyunlar bir nevi bir şeyi farklı olarak ele alma ütopyasıdır. Ortak olarak bir şeyi yapmada ve üretmede herkes eşit haklara sahiptir. "Tiyatroyu savunmak için ortaya konabilecek bir motivasyon vardır: Tiyatro insanlar arasındaki iletişimdir, aynı mekânda ve zamanda birbiriyle konuşan insanlar arasındaki bir iletişimdir. Tiyatro diyaloğun gerekliliğini savunur ve zaman ve mekânı, bir sistemi veya toplum şeklini dikkate almaz. Tiyatro derinliğinde insani olan bir şeyi savunur, yani diğer insanlara hitap eden insanları esas alur." (Langbacka, s.2)

* Öğretici oyunlarda bazı şeyler duyularla tecrübe edilebilir, ancak öğretici oyunlanı teorik ve fikri bir arka planı vardır. Bu teori teorik dilde değil, aksine oyun şeklindedir. Teori ancak ortak üretim sonucunda üretilir, dünyayı daha iyi anlama denemesinde bulunulur. Ve öğretici oyun çalışması anlayışına ilişkin bir görüş daha vardır. Psikoloji analisti Ruth Cohn TZI-metodunu = Konu Odaklı Etkileşim (= ben, biz ve konunun birleştirilmesi) geliştirmiş ve her şeyi bizi çevreleyen dünya ile ilgili ve tarihsel, siyasi ve ekonomik çevreyle ilgili sorular içine yerleștirmiştir.

* Farklı araçların, tekniklerin, oyun şekillerinin ve estetik uygulamaların birbiriyle birleştirilmesi de gerekir: Başkalarının herkese açık olan çalışmalarının bir parçası mıdır? İç ve dışın, süreç ve ürünün birleştirilmesi olabilir mi? Bir ürün yeni bir sürecin sahibi de olabilir.

* Brecht için izleme sanatı önemliydi ve alıştırma yapılarak, gözlemlenerek, adlandırma yaparak ve düzeltme önerileri kesin hale getirilerek geliştirilmeliydi. 
BU HUSUS BERTOLT BRECHT'in KÖTÜ ve ASOSYAL BAAL ÖRNEĞINDE GÖSTERILMISTTIR

* Herkes oyun içinde olamayacağı için, bu belki de oyun oynama sevgisini destekleyecek pratik bir öneridir: Herkes kimi zaman oyuncudur, kimi zaman da seyircidir. Herkes her rolü veya her farklı oyun şeklini bir keresinde denemelidir. Bundan ne çıkacağı hiç belli olmaz.

* Denemelerin ilgi uyandıracak şekilde olmasına dikkat edilmelidir. Her tepkiyi, her düşünceyi ve her oyun ve yorum fikrini oyun içinde uygulanması takip etmelidir ve prova örnek şekilde yapılmalıdır. Yani eleştiri her zaman pratik, konuya ve bedene ilişkin olarak yapılmalıdır.

* Tiyatro oyun seminerlerinde uzun ara verildiğinde gevşeme ve tanışma alıştırmalan yapılmasına özen gösterilmelidir. Bu kadar teşvik edilmiş bir bünye ruhu da gevşetir. Gruba yeni katılanlar oyun grubunun ve süjenin dinamizmini değiştirebileceği haturda tutulmalıdır.

* Sahne donatımı ile daha sonra da oyun oynamak motive eder ve bazen oyun taslağı ile ilgili farklı bakış açıları sağlar. Kıyafet kendine özgü bir ifade aracıdır. Sadece tipik bir kıyafetin seçimi ilginç olabilir veya kostüm ya da sahne donatımı beklentilerin aksine seçilir.

* Tiyatro oyununda şu ayrıntılara dikkat edilmelidir. Bir sahnenin düzenlenmesinde sahne daha önemli ve daha büyük olabilir.

* Elde metin olmadan "doğru" olarak oynama istenmesi sorunu ortaya çıkabilir. Bu anlaşılır bir durumdur. Ancak metin oyunun bir parçası olduğu için bu metin çok hızlı bir şekilde bırakılmamalıdır, sadece geçici olarak metin bırakılabilir. Elde sayfalar olduğu halde neden oyun oynamayalım ki? Biz profesyonel oyuncu değiliz ki, biz sadece iletişimsel ve şekillendirici yeteneklerini geliştirmek ve performans ortaya koymak isteyen oyun oynayan ve düşünen insanlarnz. Metin olmadan oyun oynamak tabiî ki ilginçtir. Tutulup kalındığında bu nasıl bir etki yaraturdı. Oyun kişisel özellikler üzerine değil, daha ziyade gösterme üzerine kuruludur. Bu durum bizimle de ilgilidir. Grup belki de yeni bir metin yazar veya günlük basından aldığı bir metni ekler.

* Tüm oyuncular benim fikrime uymak zorunda değildir. Sizin de kendinize ait fikirleriniz vardır ve bu fikirler hiç de kötï değildir. Bu fikirlere provalarda ve aynntılı denemelerde oyun oynarken ortaya çıkan, birlikte geliştirilen ve daha önce öngörïlemeyen fikirler de ilave edilir.

\section{Bir Eğitim Bilimcisinin Fragmanlara Yanaşılmasına Illişkin Görüşleri}

Gundel Mattenklott'tan yaptığım alıntıyı aktarıyorum (Berlin Sanat Üniversitesi Profesörï): "Fragmanlara yanaştığımız ve onlan reddetmediğimiz anda pedagojik süreçlerle ilgili görüşümüz değişir. Artık ders vererek ve eğiterek aktardığımız şeylerin çocuklarımıza, gençlere ve yetişkinlere anlatmak istediğimiz gibi bir bütünlük arz etmesi gerekmediğini ve modern sanat gibi açık olabileceğini kabul edebiliriz. Deney üretme süreci fragman karakterine uygun düşer. 
Estetik deneyde tesadüfe önemli bir yer verilir: Oyunculann müzikte, izleyici ve oyunculann tiyatrodaki spontane hareketlerinde, edebiyatta tesadüfü olarak suralanan kelimelerle yapllan oyunda, sanatsal materyalin kendine özgü anlamında doğaçlama isteği plastik sanatlardaki renk gibidir: Tesadüfün oyun sahası büyük ya da küçük olabilir, sanatçı tesadüfü kullanabilir ve değer yargılarına uygun olarak yönetebilir veya kendini tesadüfe daha fazla bağımlı hale getirebilir. Pedagoji uygulamalarında benzer bir şekilde davranabiliriz. Çalıștığımız insanlanın özelliklerine göre birlikte oyun oynamaktan duyduklan sevince daha fazla hareket sahası verebilir veya bu sevinci daha güçlï bir şekilde teşvik edebiliriz: Konunun kendisinin etki yapmasını veya sanatsal bir şekilde sahnelenmesini teşvik edebiliriz. " (Mattenklott, s. 4).

\section{Bir Tiyatro Yönetmeninin Brecht'’in Fragmanlarına Illişkin Görüşleri}

Manfred Wekwerth' in Brecht'in "Jakob Gehherda'nin ekmekçi dükkânı ve gerçek hayatt" adlı fragman oyunlarının gösterilmesinin planlanmasına ilişkin olarak 1967 yılında yaptığı açıklamalarından yaptığım alıntılan aktarıyorum: "Fragmanlanın gösterimi ile Brecht'in tüm çalışmalarının tarihi olaylanın ve farklı alanlardaki konulann ele alınması olanağını veren uygun bir aracın bulunması için her bir oyunun bu tarihi olayları ve farklı alanlardaki konulan temsil ettiği bir süreç olarak anlaşılması gerektiği gösterilecektir. Bu fragmanlar bu metodun araşturılması için oyunlar kadar manidardır. Bu fragmanlar teknik ve artistik açıdan oyunlar seviyesindedir, ancak belirli bir aşamada bundan aynlırlar. Bu yolla cevaplann yanı sıra hem gerçeklikteki hem de yazar nezdindeki mevcut objektif güçlüklere işaret eden soru demetleri de sağlarlar. Bunlar gerçek krizlerdir... Fragmanların gösterimi izleyici bölümünde bile birlikte çalışan bir kimse olarak Brecht'in karşısına çıkıldığında Brecht ile çalışılabileceğini gösterecektir. Buna göre sadece Brecht ile bir şeyleri iletmek önemli değildir, aym zamanda da iletimi bizzat iletmek veya Brecht'in dediği gibi öğrenilmesi gereken şeyin öğrenme olması önemlidir. "(Wekwerth, s.191f.).

\section{Sonuç}

Brecht'in bize biraktığı Kötï ve Asosyal Baal oyununun sahneleri, taslaklan ve fragmanlan diyalektik-çeliş̧ili süje oluşumu prosedürü olarak okunabilir (Sosyalleşme üretimi olarak: Benim. Ama ben sahip değilim. Bunun için önce biz. Ernst Bloch İzler (1930) adlı eserinin başında burada kastedilenleri bu şekilde ifade eder. (Bakınız. Koch 2001): „Öğrenme kabul etme işlemi olduğu kadar aynı zamanda da uzaklaştırma işlemidir, bir eleştiri işlemidir. Öğrenme olgusu, beni değiştirmeli ve aym zamanda ben olarak kalmayı sağlamalıdır. " (Brecht, 1938)."Riskli toplumlardaki bireyselciliğin ve/veya öznelliğin oluşumu/oluşturulmasına ilişkin yeni sosyolojik düşünceler “ (Ulrich Beck) Brecht'in Kötü ve Asosyal Baal oyununun sahneleri, 
BU HUSUS BERTOLT BRECHT'in KÖTÜ ve ASOSYAL BAAL ÖRNEĞNDE GÖSTERILMISTTIR

taslaklan ve fragmanlan ile yazışıyormuş gibi görünür (Bakınız. Koch 2003). Brecht 1941 yılının Şubatında şöyle söyler: „Birey bir kitleye benzer bir şekilde bize sürekli bir gelişim içinde bulunan çelişkili bir kompleksten daha öte bir şey olarak görünür. Birey dışarıya karşı bir bütün olarak görünür ve bu yüzden farklı eğilimlerin her bir davranışın uzlaşmayı temsil edecek şekilde ağırlık kazandığı az ya da çok mücadeleci bir çokluktur. “

\section{Kaynaklar}

Brecht, B.(1968) Baal. Der böse Baal der asoziale. Texte, Varianten, Materialien, Kritik. Hrsg und komm. von Dieter Schmidt. Frankfurt am Main.

Brecht, B. Der Dreigroschenprozeß, GBA Bd. 21.

Brecht, B. Journale II. In: GBA (= Große kommentierte Berliner und Frankfurter Ausgabe), Bd. 27.

Brecht, B. Journale I. In: GBA, Bd. 26.

Brecht, B. Zur Theorie des Lehrstücks. In: Werkausgabe, Bd. 17.

Koch, G. (2003). Ich ist ein Anderer. Eine pädagogische Denkfigur für soziale Kulturarbeit? In: H. Kleve, G. Koch, M. Müller (Hrsg.): Differenz und Soziale Arbeit. Sensibilität im Umgang mit dem Unterschiedlichen. Berlin, Milow, Strasburg.

Koch, G.(1995): Theatralisierung von Lehr-Lernprozessen. Milow, Berlin.

Koch, G.(2001): „Ich bin. Aber ich habe mich nicht. Darum werden wir erst“. In: Angela Haubner u. a. (Hrsg.): Warum spielt der Mensch ... Theater? Hannover.

Krabiel, K.D.(1993) Brechts Lehrstücke. Stuttgart, Weimar.

Langbacka, R., zit. bei R. Seppäla.(1996).Ralf Langbacka's thirst for dialogue. In: Finnish Theatre Finlandais., H. 50.

Lewin, K.(1985) Experimente über den sozialen Raum. In: T. Brocher, T. Kutter (Hrsg.): Entwicklung der Gruppendynamik. Darmstadt.

Mattenklott, G.(1994) Ganzheit oder Fragment? In: Spiel \& Theater, H. 152.

Portmann, M.(1997) zitiert bei hs.: Fabrik liefert Ideenschmelztiegel. In: Neues Gera, 4. 10. 
Rumpf, H.(1979) Worauf zu achten wäre. Aufmerksamkeitsrichtungen für die Friedenserziehung. In: R. Steinweg (Hrsg.): Friedensanalysen, Bd. 10. Frankfurt am Main.

Steinweg, R.(1995) Lehrstück und episches Theater. Brechts Theorie und die theaterpädagogische Praxis. Frankfurt am Main.

Steinweg, R.(2004) Lehrstückspiel als Methode der kollektiven Selbstreflexion/Learning Play as a Method of Collective Self Reflection. In: G. Koch u. .a (Hrsg.): Theaterarbeit in sozialen Feldern/Theatre Work in Social Fields. Frankfurt am Main.

Wekwerth, M.(1967) Notate, Frankfurt am Main. 


\title{
Theater-Stück-Fragmente Stimulieren Kreativität und Sie Benötigen \\ Kreatives Spielerisches Verhalten - Gezeigt am Beispiel von Bertolt Brechts DER BÖSE BAAL DER ASOZIALE
}

\author{
Gerd Koch ${ }^{*}$ \\ Alice-Salomon Faculty
}

\begin{abstract}
Pädagogik als methodische Erziehungswissenschaft und als praktisches Tun bezieht sich auch auf Theater, auf Theatertexte, auf Stücke, auf Inszenierungen. Das geschieht nicht nur im Literaturunterricht an Schulen oder in Arbeitsgemeinschaften und Studienprojekten, die einen Theatertext zur Auffihrung bringen wollen. Vielmehr strukturiert das kommunikativ-kreative Modell des Theaters Bildungsprozesse außerhalb von Schulen und auch Forschungs- und Untersuchungsvorhaben und ergänzt das herkömmliche Theater. Dieser Ansatz der Pädagogik in Theorie und Praxis wird im deutschen Sprachgebiet neuerlich als Theaterpädagogik bezeichnet. Wie dieses nun in kreativer und vielfältiger Weise zu üben ist in der Hochschulausbildung von Studentinnen und Studenten, wird im Folgenden am Beispiel der Theater-Stück-Fragmente aus Bertolt Brechts Beschäftigung mit seinem BAAL-Stoff gezeigt. Es wird auf Ideen der Brechtschen Lehrstück-Theorie und -Praxis in methodischer und kreativer Weise Bezug genommen, und es werden Arbeitsempfehlungen für das Lehren und Lernen an Hochschulen gegeben.
\end{abstract}

Schlïssel wort: Theater spiel, Bertolt Brecht, Lehrstück

\section{Theaterpädagogik}

Der vom Erziehungswissenschaftler und ehemaligen Studienrat Horst Rumpf im Zusammenhang mit der Brechtschen Lehrstück-Diskussion und Friedensforschung und erziehung um Reiner Steinweg empfohlene „Ansatz beim Szenischen“ stellt eine neue Weise des Lehrens und Lernens, des Erfahrungenmachens dar. „Der Ansatz beim Szenischen, bei der Arbeit von Subjekten an der Konstitution ihrer Erfahrungswelt kostet mehr Zeit als die Beschränkung auf den puren Inhalt ... Probieren, Umwege, Irrwege bei der Erforschung der neuralgischen Punkte und Phasen von Lernprozessen sind nicht als Zeitverlust zu verbuchen ...“ (Rumpf, S. 165). Forschung, Erziehung, Lehren und Lernen bilden in einem vom Theater strukturierten Bildungsvorgang ein Ganzes. Der klassische deutsche Begriff von „Bildung“ bekommt einen Teil seiner Sinnlichkeit zurück: etwas wird gebaut, gebildet, hergestellt; etwas hat ästhetische, imaginative, ikonographische Qualität; ein Bild ist als Kunstwerk eine mehrdeutige Erscheinung; Bildung wird zur prismatischen Erscheinung, läßt Interpretationen

\footnotetext{
•Prof. Dr. Alice-Salomon Faculty, E-mail: Koch@asfh-berlin.de
} 
zu. Theatral fundierte Bildungsprozesse vereinigen die unterschiedlichen Konnotationen von „formazione“, „cultura“, „educazione“ und ,istruzione“ (wie es im Italienischen heißt).

"Theaterpädagogik meint die Verwendung des Theatralen, von Theatralität in Lehr- und Lernprozessen. Wobei Lehr- und Lernprozesse ... gesellschaftliche und/oder gesellige Prozesse des Veränderns von Wissen und Verhalten im Individuum und zwischen Individuen (sind). Das Theatrale, die Theatralität oder das Prinzip Theater will ich verstehen als Zeige-, Handlungs-, Anschauungs- und Darstellungsweise alltäglicher wie künstlerischer Art: Straßenszenen und Theaterszenen sind ebenso zu erinnern wie das Zelebrieren einer Messe oder eines Prozesses oder das Ausstellen politischer Gesten auf dem parlamentarischen Parkett ...“ (Koch 1995, s. 11).

Mario Portmann von der Theaterschule in Gera setzt diesen Akzent: „Theaterpädagogik erzieht nicht mittels Theater, sondern will von den Zwängen und Hemmnissen befreien, die sich zwischen uns und unsere Erfindungen, unsere Kreativität stellen".

Ich habe als Theaterpädagoge mit den Entwürfen, Szenen und Fragmenten von Bertolt Brechts Bösem Baal dem asozialen experimentiert - dabei bin ich weniger streng nach den ,Regeln' des Lehrstücks (vgl. Steinweg 1995, 2004) verfahren, sondern habe die wie immer vorhandene Textvorlage Brechts als Theater-Spiel-Anlaß genommen bzw. den Text als Mit-Spieler eingeführt: Ihm mußte man begegnet sein, aber nicht unbedingt folgen: Begegnung, nicht Folgsamkeit und Bindung. Brechts Theatertexte nehme ich als Gebrauchstheater-Vorlagen.

Brecht schreibt etwa 1938: „Lernen, ein Akt des Aufnehmens und zugleich Abstoßens. Ein Akt der Kritik. Ebenso gut machen und besser machen. Mich ändern und zugleich ein Ich bleiben."

\section{Brecht zur Theorie-Praxis seiner Lehrstücke (auch ,learning plays“ von ihm genannt)}

„Das Lehrstiuck lehrt dadurch, daß es gespielt, nicht dadurch, daß es gesehen wird. Prinzipiell ist für das Lehrstück kein Zuschauer nötig, jedoch kann er natürlich verwertet werden. Es liegt dem Lehrstiick die Erwartung zugrunde, daß der Spielende durch die Durchführung bestimmter Handlungsweisen, Einnahme bestimmter Haltungen, Wiedergabe bestimmter Reden und so weiter gesellschaftlich beeinflußt werden kann. Die Nachahmung hochqualifizierter Muster spielt dabei eine große Rolle, ebenso die Kritik, die an solchen Mustern durch ein überlegtes Andersspielen ausgeübt wird. Es braucht sich keineswegs um die Wiedergabe gesellschaftlich positiv zu bewertender Handlungen und Haltungen $\mathrm{zu}$ handeln; auch von der (möglichst 
großartigen) Wiedergabe asozialer Handlungen und Haltungen kann erzieherische Wirkung erwartet werden -- Die Form der Lehrstücke ist streng, jedoch nur, damit Teile eigener Erfindung und aktueller Art leichter eingefügt werden können. “ (Brecht, Zur Theorie, s. 1024, Hervorhebungen nicht im Original).

„im lehren muß das lernen enthalten bleiben. die lehrstücke sind nicht lediglich parabeln, die eine aphoristische moral mit zeigebildern ausstatten, sie untersuchen auch, deshalb ist es nicht nötig, daß die lösungen allzu sehr konzentriert und auf allzu simple formen gebracht werden.“ (Brecht nach Krabiel, s.298) Gerade die Unvollkommenheit, das Brüchige und der Impulscharakter der Textsorten macht sie wertvoll für die theaterpädagogische Arbeit.

Brecht notiert Anfang 1943 im amerikanischen Exil: „Neue Bekanntschaft: Kurt Lewin, der in Iowa unter Scouts und Arbeitern ,Führerbenehmen ' ausbildet und mich einlädt, interessiert an dem ,Bösen Baal dem asozialen“." (Brecht Journale II, s.150) Kurt Lewin (bedeutender, begründender experimenteller Sozialpsychologe; im Exil wie Brecht) schreibt 1939 einen Aufsatz „Experimente über sozialen Raum“ - zur Lösung sozialer Konflikte: „Ich bin der Überzeugung, daß es möglich sei, in der Soziologie und Sozialpsychologie Experimente vorzunehmen, die mit dem gleichen Recht als wissenschaftliche Experimente zu bezeichnen sind wie die in der Physik und Chemie. Ich bin überzeugt, daß es einen sozialen Raum gibt, der alle wesentlichen Einheiten eines wirklichen empirischen Raumes besitzt und er genausoviel Aufmerksamkeit von seiten der Forscher auf dem Gebiet der Geometrie und Mathematik verdient wie der physikalische Raum, obwohl er nicht physikalischer Art ist. Die Wahrnehmung des sozialen Raumes und die experimentelle und begriffsmäßige Erforschung der Dynamik und der Gesetze der Vorgänge im sozialen Raum sind von grundlegender theoretischer und praktischer Bedeutung“ (Lewin, s.41) „Ich bin überzeugt, daß die wissenschaftliche Soziologie und Sozialpsychologie auf der Grundlage einer intimen Verbindung von Experimenten mit empirischer Theorie soviel oder mehr für die menschliche Verbesserung leisten können, wie es die Naturwissenschaften getan haben. Die Entwicklung einer solchen realistischen unmystischen Sozialwissenschaft und die Möglichkeit ihrer fruchtbaren Anwendung setzen jedoch das Vorhandensein einer Gesellschaft voraus, die an die Vernunft glaubt.“ (Lewin, s.52) Die Welt soll für Lewin, ganz brechtisch gesagt, so ein , sicherer und freundlicher Aufenthaltsort' werden: „Der Glaube an die Vernunft bedeutet Glauben an die Demokratie, denn sie gewährt den vernünftig denkenden Partnern Gleichheit. Es ist daher kein Zufall, daß erst beim Entstehen der Demokratie zur Zeit der amerikanischen und französischen Revolutionen die Göttin der ,Vernunft' in der modernen Gesellschaft inthronisiert wurde. Und wiederum ist es kein Zufall, daß die erste Handlung des modernen Faschismus in jedem Lande 
darin bestand, offiziell und mit Nachdruck diese Göttin zu entthronen und statt dessen auf dem Gebiet der Erziehung und des Lebens vom Kindergarten bis zum Tode Gefühle und Gehorsam zu alles bestimmenden Prinzipien zu machen." (Lewin, s.52)

Am 7.3.1941 schreibt Brecht - theaterpädagogisch: „Der große Irrtum, der mich hinderte, die Lehrstückchen vom ,Bösen Baal dem asozialen' herzustellen, bestand in meiner Definition des Sozialismus als einer Großen Ordnung. Er ist hingegen viel praktischer als Große Produktion zu definieren. Produktion muß natürlich im weitesten Sinne genommen werden, und der Kampf gilt der Befreiung der Produktivität aller Menschen von allen Fesseln. Die Produkte können sein Brot, Lampen, Hüte, Musikstücke, Schachzüge, Wässerung, Teint, Charakter, Spiele usw. usw.“ (Brecht Journale I, s.468, Hervorhebung im Original)

Es war für die theaterpädagogische Arbeit ein Glücksfall, als 1969 Dieter Schmidt Bertolt Brechts Fragmente zum Themenkomplex Der böse Baal der asoziale herausbrachte: Diese Texte dürfen nicht verwechselt werden mit Brechts genialem Frühwerk Baal. Zwar bestehen auch dazu Hinweise in den fragmentarischen Stücken vom Bösen Baal dem asozialen, und Brecht hat sich mit der komplexen Baal-Thematik Zeit seines Lebens befaßt. Die Texte sind nicht in der Werkausgabe enthalten. Sie finden sich seit 1997 in Band 10 der Großen kommentierten Berliner und Frankfurter Ausgabe.

Die von Schmidt vorgelegte Sammlung der Fragmente zum Bösen Baal beginnt mit einer - so würden Theaterpädagogen sagen - Rollenspielanregung: Baal soll ,auftauchen als gast/hure/kaufmann (stiere)/ingenieur (will nur das experiment)/hilfsbedürftiger - bittsteller (er bedeutet das ausgebeutetseinwollen aus)/liebhaber der natur/demagoge/arbeiter(streikbrecher)/mutter/historiker/soldat/liebhaber -- als pfaffe/als beamter/die 2 mäntel“. (Brecht Baal, s.78)

Bewußt oder zufällig steht diese „Spielanweisung“ am Anfang. Theaterpädagogisch wird der richtige Akzent gesetzt. Die Spielenden sollen sich auf ungleichzeitiges Rollen-Wechsel-Spiel gleich anfangs einlassen. Damit ist ein methodischer Tenor angeschlagen - der aber mit anderen theater- und/oder spielpädagogischen Ideen erweitert und konkretisiert werden muß. Also: Spielfähigkeit muß auch in der Lehrstück-Pädagogik mitgeübt werđen. Dies ist vor allem wichtig, wenn man sehr fragmentarische, abstrakt gebliebene Szenen/Skizzen zum Spielanlaß nehmen will. 


\section{„DER BÖSE BAAL}

als paßbeamter. eine frau kämpft um das leben ihres bruders. der beamte erfüllt sämtliche formalitäten. eile ist alles (kanonendonner, uhr)“ (Brecht Baal, s. 81).

Solche Szenen/Skizzen fordern heraus, ein „überlegtes Andersspielen“, ein „Untersuchen“ und Einbringen von „eigener Erfindung ... aktueller Art" vorzunehmen - so Brecht in seiner Lehrstück-Theorie. Stärker ausgearbeitete Szenen stimulieren etwas anderes, nämlich das Generieren eigener Erzählungen und Lebensszenen (gleich: Erinnerungsarbeit), z. B. vermittels der letzten Szene vom Bösen Baal dem asozialen, die Brecht im Sommer 1954 schrieb:

„Ein Mann ist eingetreten.

DER MANN Herr Inzipient. Sie brauchen heute nicht ins Büro zu kommen. Er hält ihm einen blauen Brief hin. Ich bekomme 20 Pfennig. Gibt ihm den Brief.

BAAL legt sich aufs Bett: Was steht drin, Baumann?

DER AMTSDIENER liest: Werter Herr Baal! Da für Genies Ihrer Sorte eine so ermüdende Arbeit wie die eines Schreibers, der Sie sich ja selbst tagelang entziehen, nicht mit dem Verantwortungsgefühl der Behörde vereinbar ist, sind Sie ab 1. Juni aus den städtischen Diensten entlassen. Unterschrift: der Chef selbst. Es tut mir leid, Herr Inzipient.

BAAL Baumann, manchmal träume ich von einem See, der ist tief und dunkel und zwischen DER AMTSDIENER Unter diesen Umständen verzichte ich auf die 20 Pfennig, obwohl ich auch leben muß. Habe die Ehre! $A b$.

BAAL lacht." (Brecht Baal, s. 90 f.)

Solche Texte sind (an-)leitende „Mitspieler“ im kollektiven, experimentellen Spielprozeß, im Versuch - sie stehen auch zur Disposition (gleich: Andersspielen oder auch "Zerschmeißen“, wie es in Brechts Fatzer heißt; der Baal-Stoff gibt eine weitere Spiel-Regel: „einverstanden sein heißt auch: nicht einverstanden sein").

Etwa folgende Begriffe oder Themen sind den Baal-Fragmenten inhaltlich und/oder methodisch eingeschrieben: Herr und Knecht; Einzelner und Gruppe/Kollektiv; Abhängigkeiten; Armut und Reichtum; Sinnlichkeit und Kunst gegen/und/oder materielle 
Interessiertheit; A-Sozialität als positives Modell/als Wunsch; Konstruktion/Dekonstruktion; Demontage/Montage; Arbeiten in gesellschaftlichen Furchtzentren usw.

Für den germanistischen oder theaterwissenschaftlichen Umgang mit Brechts Fragmenten sind andere Blicke wichtig als für den handlungsorientierten theaterpädagogischen. Ich nenne einige "hints for use“, einige Spiel-Gebrauchsanweisungen, die ich an Selbstlerngruppen des Lehrstïckspiels verteile:

\section{Gebrauchsanregungen für das Spiel mit Fragmenten}

* In allen Gruppen muß das Lehrstück als Ganzes bekannt gemacht werden, auch wenn nur Teile bearbeitet werden oder in verschiedenen Theater-Spiel-Gruppen arbeitsteilig gespielt wird.

* Wichtig ist, daß viele Proben und Gesten-Experimente gemacht werden. Nicht zu schnell auf die eine Spiel-Fassung kommen. Das Lehrstück lehrt dadurch, daß es gespielt wird

* Erholungspausen gut einsetzen und wirklich zur Erholung, zum Setzenlassen des Erspielten nutzen! Also: Pausen immer schon dann machen, wenn man/frau noch nicht ganz außer Atem ist!

* Und: Gesprächsnunden von Spielrunden trennen. Die Wirklichkeit der SpielerInnen mit hineinbringen: öffentliche Lemprozesse, die offen für Variationen und Abweichungen sind, veranstalten. „Die Widersprüche sind die Hoffnungen“ (Brecht Dreigroschenprozeß, S. 448). Und: Fragen sind besser als Antworten. Spielemachen ist besser als bloß Hören und Gucken.

* Nicht genug kann betont werden: Lehrstücke sind Handlungsexperimente, sind Selbstverständigungsangebote. In der Arbeit mit ihnen sollen Trennungen von ProduzentInnen und KonsumentInnen aufgehoben werden. Es soll ein kontroverser Produktionsvorgang entstehen. Das Lehrstück ist gewissermaßen ein Angebot. Es steht auch zur Disposition - wie auch die sozialen und ästhetischen Kontexte der Mitspielerinnen zur Kritik anstehen.

* Die Stücke sind nicht für SchauspielerInnen gedacht, obgleich ja alles im Medium des Theaters stattfindet ...

* Man sollte keine Angst vorm Spielen haben (obwohl man die auch hat). Man sollte - auch als SpielleiterIn - die ersten Unsicherheiten, die „Schwellenängste“ beim allerersten Mal des eigenen Theater-Spielens erinnerlich halten. Auch Theater-Spielen ist etwas Einfaches, das schwer zu machen ist.

* Lehrstücke sind ganz unmittelbar ein Übungsfeld für eine neue Kommunikation. Sie sind Übungsstücke für dialektisches, ungleichzeitiges, widersprüchliches Umgehen mit Personen, 
Texten, Formen, Inhalten, Absichten, Stimmungslagen. Und sie sind ein Stück Utopie eines anderen Umgangs miteinander: Gleichberechtigt im gemeinsamen Tun/Produzieren. "There is one motivation, the sole one that can be presented for the defence of theatre: theatre is communication between people, people who speak to each other in the same space and time -Theatre defends the necessity for dialogue, irrispective of time and space, of system or form of society. It defends something deeply human: people, who speak to other people." (Langbacka, s.2).

* Im Lehrstück läßt sich einiges sinnlich erfahren, aber die Lehrstücke haben auch einen theoretisch-konzeptionellen Hintergrund. Theorie nicht in Theoriesprache, sondern in SpielForm. Durch gemeinsames Produzieren wird Theorie erst hergestellt, wird ein Versuch unternommen, die Welt besser zu bestehen. Und noch eine Idee zum Verständnis der LehrstückArbeit: Von der Psychoanalytikerin Ruth Cohn gibt es die sog. TZI-Methode = Themenzentrierte Interaktion (= Verbindung von Ich, Wir und Thema/Text) und alles das eingebettet in Fragestellungen des uns umgebenden "globe", der historischen, politischen, ökonomischen Umwelt.

* Es gilt auch, verschiedene Medien, Techniken, Spielformen, ästhetische Praxen miteinander zu verbinden: ein Stück anderer Öffentlichkeitsarbeit?! Eine Verbindung von Innen und Außen, von Prozeß und Produkt. Auch ein Produkt kann/soll Urheber eines neuen Prozesses sein.

* Für Brecht war zusätzlich die Zuschaukunst wichtig und sollte entwickelt werden. Üben: Beobachten, Benennen, Korrekturvorschläge präzisieren.

* Da nicht alle immer im Spiel sein können, ist dies vielleicht ein praktischer, die Spielfreude stützender Vorschlag: Jeder ist mal Spieler, mal Zuschauer. Und: jede/r sollte (besser: muß) jede Rolle oder jede Variante mal ausprobieren. Man glaubt gar nicht, was dabei schon herauskommen kann!

* Immer bedenken: Die Versuche sind es, die interessieren. Auf jede Reflexion, auf jeden Gedanken, auf jede Spiel- und Interpretationsidee muß eine Umsetzung ins Spiel, eine Probe aufs Exempel folgen. Also: Die Kritik soll immer praktisch, gegenständlich, körperlich werden.

* Auch im Fortgang des Theater-Spiel-Seminars, vor allem bei längeren Unterbrechungen, daran denken, daß Lockerungs- und Kennenlern-Übungen gemacht werden müssen. Vielleicht lockert ein so angeregter Körper auch den Geist! Bedenken: Neuhinzukommende verändern die Dynamik der Spielgruppe und eines jeden Subjektes! 
* Mit Requisiten usw. später auch zu spielen, motiviert und bietet manchmal noch andere Blicke auf die Spielvorlage. Die Kleidung stellt eine eigene Sprache dar. Die Auswahl nur eines typischen Kleidungsstücks kann interessant sein oder man wählt Kostium oder Requisit quer zu Erwartungen aus.

* Auf sog. Kleinigkeiten, auf das Nebenbei im Theaterspiel achten: Im Fortgang einer Szene könne sie wichtiger und größer werden.

* Es kann das Problem auftreten, daß man ohne Text in der Hand (endlich) ,richtig“ spielen möchte! Verständlich. Aber, weil der Text ein Mitspieler ist, sollte der nicht sehr schnell und nur vorübergehend verabschiedet werden. Warum nicht mit dem Blatt in der Hand spielen? Wir sind doch keine Berufs-Schauspieler, sondern spielende und denkende Menschenkinder, die ihre kommunikativen und gestalterischen Potenzen entfalten, zur Performanz bringen wollen. Interessant ist schon, mal ohne Text zu spielen: Wie wirkt das, was blieb hängen; was wurde wie umschifft oder geglättet ...?! Das Stück ist ja auch nicht auf persönliches Identifizieren, sondern eher auf Zeigen angelegt ... Betrifft uns aber doch ... Vielleicht schreibt die Gruppe einen neuen Text oder fügt einen aus der Presse vom Tag mit ein ...?!

* Im übrigen: Nicht alle SpielleiterInnen/SpielerInnen brauchen sich an meine Ideen zu halten sie haben ja selber welche und nicht die schlechtesten! Hinzu kommen noch die Ideen, die sich spielend während der Proben/der Detail-Experimente einstellen, die mit entwickelt werden, die man vorher gar nicht voraussah (das Entwickeln einer Gruppen-Theater-Spiel-Kultur beachten!).

\section{Eine Erziehungswissenschaftlerin zum Einlassen auf das Fragmentarische}

Ich zitiere Gundel Mattenklott (Professorin an der Universität der Künste Berlin): „Im Augenblick, in dem wir uns auf das Fragmentarische einlassen und es nicht abwehren, verändert sich unsere Einstellung zu pädagogischen Prozessen. Wir können nun zulassen, daß auch das, was wir unterrichtend und erziehend vermitteln und wie wir es unseren Kindern, Jugendlichen und Erwachsenen nahebringen wollen, keine Vollständigkeit haben muß, daß es so offen und unabgeschlossen sein darf wie die Kunst der Moderne. Ihrem fragmentarischen Charakter entspricht als Prozeß der Herstellung das Experiment. Im ästhetischen Experiment wird dem Zufall ein bedeutsamer Platz eingeräumt: der Improvisationslust der Spieler in der Musik, den spontanen Aktionen von Zuschauern und Schauspielern im Theater, dem Spiel der zufällig aufeinander treffenden Wörter in der Literatur, dem Eigensinn der künstlerischen Materialien, wie der Farbe in der bildenden Kunst. Der Spielraum des Zufalls kann größer oder kleiner sein, der Künstler ihn in seinen Dienst nehmen und ihn seinen Vorstellungen entsprechend lenken 
oder sich mehr von ihm tragen lassen. In der pädagogischen Praxis können wir uns ähnlich verhalten. Wir können je nach Selbständigkeit der Menschen, mit denen wir arbeiten, ihrer eigenen Mitspielfreude mehr Freiheit geben oder sie stärker anregen: den Gegenstand für sich wirken lassen oder kunstvoll inszenieren." (Mattenklott, s. 4).

\section{Ein Theaterregisseur zum Nutzen der Brechtschen Fragmente}

Ich zitierte aus Manfred Wekwerths Bemerkungen von 1967 zu einer geplanten Aufführung der Brechtschen Fragmente Der Brotladen und Das wirkliche Leben des Jakob Gehherda: „Mit einer Aufführung der Fragmente soll u. a. gezeigt werden, daß alle Arbeiten Brechts nur als ein Prozeß zu verstehen sind, wobei die einzelnen Stücke eine Art Einkreisung historischer Vorgänge und Themen von verschiedenen Seiten darstellen, um irgendwo den herausstehenden Hebel zu finden, durch den man sie in den Griff bekommt. Für das Studium dieser Methode sind die Fragmente so aufschlußreich wie die Stücke. Sie stehen technisch und artistisch auf der Höhe der Stücke, brechen freilich in einer bestimmten Phase ab. Dadurch liefern sie neben Antworten auch Bündel von Fragen, die durch ihre Nichtbewältigung hinweisen auf vorhandene objektive Schwierigkeiten sowohl in der Wirklichkeit als auch beim Schriftsteller: Es sind echte Krisen ... Eine Aufführung der Fragmente soll zeigen, daß man mit Brecht nur arbeiten kann, wenn man ihm - versehen mit seiner Methode - als Mitarbeiter gegenübertritt, auch im Zuschauerraum. So kommt es nicht nur darauf an, ,etwas' mit Brecht zu ,vermitteln', sondern es kommt auch darauf an, die Vermittlung selbst zu vermitteln oder wie Brecht es ausdrückte: es ist das Lernen, was gelernt werden muß“" (Wekwerth, S. 191f.).

\section{Schlußbemerkungen}

Dievon Brecht hinterlassenen Szenen, Entwürfe, Fragmente zum Bösen Baal dem asozialen lassen sich als eine Prozedur dialektisch-widersprüchlicher Subjekt-Konstitution lesen (als Produktion von Sozialisation: „Ich bin. Aber ich habe mich nicht. Darum werden wir erst“ - so formuliert Ernst Bloch am Beginn seiner Spuren (1930) das hier Gemeinte (vgl. Koch 2001): „Lernen, ein Akt des Aufnehmens und zugleich Abstoßens. Ein Akt der Kritik ... Mich ändern und zugleich ein Ich bleiben“ (Brecht, um 1938). Neuere soziologische Überlegungen zur Konstitution/Konstruktion von Individualität und/oder Subjektivität in „Risikogesellschaften“ (Ulrich Beck) scheinen mit Brechts Entwürfen, Szenen, Fragmenten aus dem Bösen Baal zu korrespondieren (vgl. Koch 2003). Brecht notiert im Februar 1941: „Das Individuum erscheint 
uns immer mehr als ein widerspruchsvoller Komplex in stetiger Entwicklung, ähnlich einer (physikalischen, Anm. gk) Masse. Es mag nach außen hin als Einheit auftreten und ist darum doch eine mehr oder minder kampfdurchtobte Vielheit, in der die verschiedensten Tendenzen die Oberhand gewinnen, so daß die jeweilige Handlung nur das (! eine süddeutsche SprachEigentümlichkeit Brechts ) Kompromiß darstellt".

\section{Literatiir}

Brecht, B.(1968) Baal. Der böse Baal der asoziale. Texte, Varianten, Materialien, Kritik. Hrsg und komm. von Dieter Schmidt. Frankfurt am Main.

Brecht, B. Der Dreigroschenprozeß, GBA Bd. 21.

Brecht, B. Journale II. In: GBA (= Große kommentierte Berliner und Frankfurter Ausgabe), Bd. 27.

Brecht, B. Journale I. In: GBA, Bd. 26.

Brecht, B. Zur Theorie des Lehrstücks. In: Werkausgabe, Bd. 17.

Koch, G. (2003). Ich ist ein Anderer. Eine pädagogische Denkfigur für soziale Kulturarbeit? In: H. Kleve, G. Koch, M. Müller (Hrsg.): Differenz und Soziale Arbeit. Sensibilität im Umgang mit dem Unterschiedlichen. Berlin, Milow, Strasburg.

Koch, G.(1995): Theatralisierung von Lehr-Lernprozessen. Milow, Berlin.

Koch, G.(2001): „Ich bin. Aber ich habe mich nicht. Darum werden wir erst“. In: Angela Haubner u. a. (Hrsg.): Warum spielt der Mensch ... Theater? Hannover.

Krabiel, K.D.(1993) Brechts Lehrstücke. Stuttgart, Weimar.

Langbacka, R., zit. bei R. Seppäla.(1996).Ralf Langbacka's thirst for dialogue. In: Finnish Theatre Finlandais., H. 50.

Lewin, K.(1985) Experimente über den sozialen Raum. In: T. Brocher, T. Kutter (Hrsg.): Entwicklung der Gruppendynamik. Darmstadt.

Mattenklott, G.(1994) Ganzheit oder Fragment? In: Spiel \& Theater, H. 152.

Portmann, M.(1997) zitiert bei hs.: Fabrik liefert Ideenschmelztiegel. In: Neues Gera, 4. 10. 
Rumpf, H.(1979) Worauf zu achten wäre. Aufmerksamkeitsrichtungen für die Friedenserziehung. In: R. Steinweg (Hrsg.): Friedensanalysen, Bd. 10. Frankfurt am Main.

Steinweg, R.(1995) Lehrstiuck und episches Theater. Brechts Theorie und die theaterpädagogische Praxis. Frankfurt am Main.

Steinweg, R.(2004) Lehrstückspiel als Methode der kollektiven Selbstreflexion/Learning Play as a Method of Collective Self Reflection. In: G. Koch u. .a (Hrsg.): Theaterarbeit in sozialen Feldern/Theatre Work in Social Fields. Frankfurt am Main.

Wekwerth, M.(1967) Notate, Frankfurt am Main. 